\title{
Giant Metastatic Liver Tumor of Unknown Primary Origin: Thoracic Autopsy Solves the Mystery
}

\author{
Antigony Mitselou ${ }^{1}$, Stamatis S. Papadatos ${ }^{2}$, Savvina Tsoultsidou ${ }^{1}$, Kleio Fragkouli ${ }^{1}$, Michail Mitsis ${ }^{3}$, \\ Theodoros Vougiouklakis ${ }^{1}$, Vasiliki Galani, ${ }^{4, *}$
}

\begin{abstract}
A 59-year-old male patient was hospitalized in the Internal Medicine Department for investigation of hepatic metastases from an unknown primary neoplasm. During the hospitalization the patient died from acute myocardial infarction. The autopsy revealed a $8.2 \mathrm{kilograms}$ (kg) liver that was diffusely infiltrated by whitish metastatic masses. No other tumor was detected, apart from a 2.5 centimeters (cm) pulmonary nodule next to the right intermediate bronchus that was histologically compatible with small cell lung cancer (SCLC). Despite the fact that hepatic metastases from SCLCs are common, diffuse metastatic hepatomegaly from a malignant pulmonary nodule are rarely seen. Given that the most common cause of malignancy-related death is lung cancer, early diagnosis and appropriate management of pulmonary nodules is of paramount importance.
\end{abstract}

\section{KEYWORDS}

pulmonary nodule; lung cancer; liver metastasis

\section{AUTHOR AFFILIATIONS}

${ }^{1}$ Department of Forensic Medicine and Toxicology, University of loannina, Greece

2 3rd Department of Internal Medicine, National and Kapodistrian University of Athens School of Medicine, Sotiria General Hospital, Athens, Greece

${ }^{3}$ Department of Surgery, University of loannina, Greece

${ }^{4}$ Department of Anatomy-Histology-Embryology, University of loannina, Greece

* Corresponding author: Medical School, University of Ioannina, Panepistimioupoli, 45110, loannina-Greece; e-mail: vgalani@cc.uoi.gr

Received: 26 June 2017

Accepted: 22 January 2018

Published online: 23 April 2018

Acta Medica (Hradec Králové) 2017; 60(4): 163-166

https://doi.org/10.14712/18059694.2018.14

(C) 2017 The Authors. This is an open-access article distributed under the terms of the Creative Commons Attribution License (http://creativecommons.org/licenses/by/4.0), which permits unrestricted use, distribution, and reproduction in any medium, provided the original author and source are credited. 


\section{INTRODUCTION}

A pulmonary nodule is a well-circumscribed radiological opacity which diameter does not exceed $3 \mathrm{~cm}$ (1). Due to the recent advances in medical imaging, the incidental detection of pulmonary nodules has tremendously increased (2). Malignant nodules account for $1.1 \%$ to $12 \%$ of these nodules (3) and their early detection is a great challenge for the clinicians. The liver is one of the most frequent site of metastasis from primary malignant solid tumors. Small-cell lung cancer (SCLC) comprises $15 \%$ of all lung cancers (4) and is known for its aggressive biological behavior. Liver metastasis is seen in about $50 \%$ of patients with extensive-stage SCLC and is a poor prognostic indicator (5). SCLC metastases in the liver grow according to different metastatic patterns, yet the excessive hepatomegaly due to metastatic spread is quite uncommon.

We present an unusual case of a coin-like primary pulmonary lesion and a huge metastatic liver that was necrotomically proven to be a SCLC.

\section{CASE REPORT}

A 59-year-old obese male was admitted to the Internal Medicine department for further investigation of metastatic liver disease of unknown primary origin. The patient had reported a history of coronary artery disease with percutaneous transluminal coronary angioplasty (PTCA) and was an active smoker. Since the patient died a few hours after admission, it was impossible to conduct further investigation and an autopsy was ordered. At autopsy, acute myocardial infarction was determined as the cause of death. Additionally, the macroscopic examination revealed a giant liver $(8.2 \mathrm{~kg})$ which parenchyma was almost completely replaced with metastatic tumor (Figure 1, Figure 2). A 25-mm white nodule was identified next to the right intermediate bronchus without peripheral nodules. An enlarged lymph node adjacent to the nodule was identified as well (Figure 3). No other lymph nodes were identified as enlarged or abnormal in the necrotomic examination. The other organs showed no modifications. Microscopic examination of the nodule revealed small round or oval cells. The nuclei were finely granular and hyperchromatic with unrecognizable cytoplasm, as well as absent or inconspicuous nucleoli. In some areas the cells had an elongated shape. There were areas of necrosis and vessel and lymphatic invasion (Figure 4). The same cells were also seen in the metastatic liver masses (Figure 5) and in the examined lymph node. Immunohistochemically, the cells were strongly positive for TTF-1 and CD56, moderately positive for chromogranin, synaptophysin and negative for CD45 and CD99. The proliferation index was $70-80 \%$ of the malignant cells (Figure 6). The macroscopic and microscopic features were consistant with SCLC presenting as a solitary pulmonary nodule with metastases in the liver and lymph nodes.

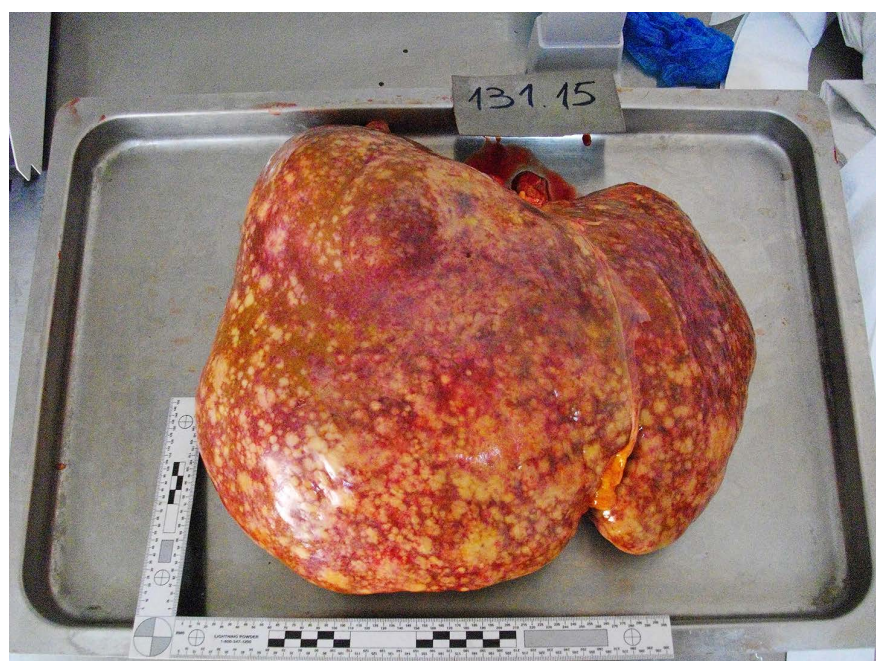

Fig. 1 Diffuse hepatomegaly with varying sized metastatic nodules.

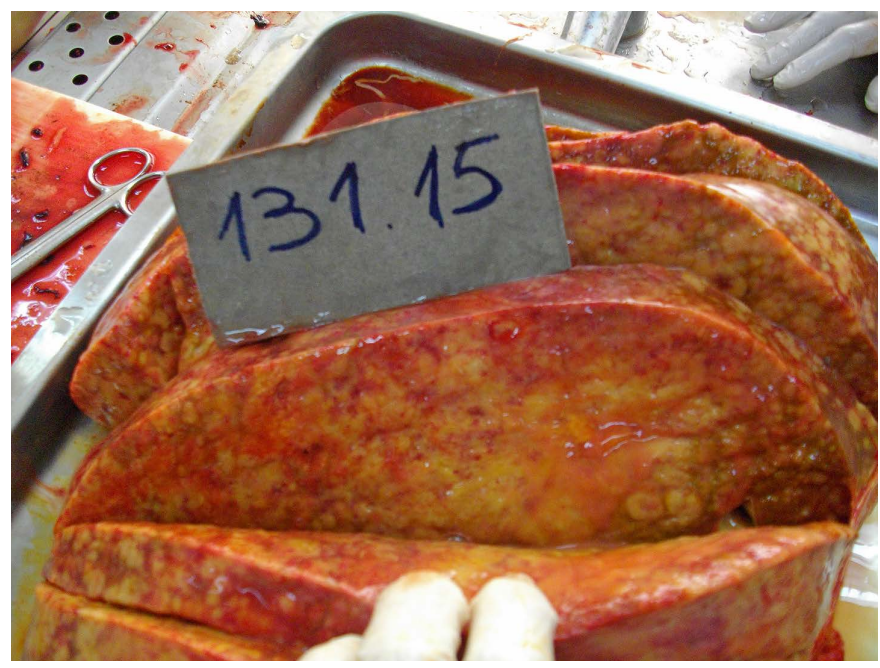

Fig. 2 The liver contained multiple and variable nodules ranging from $0.5 \mathrm{~cm}$ to $3 \mathrm{~cm}$ in size.

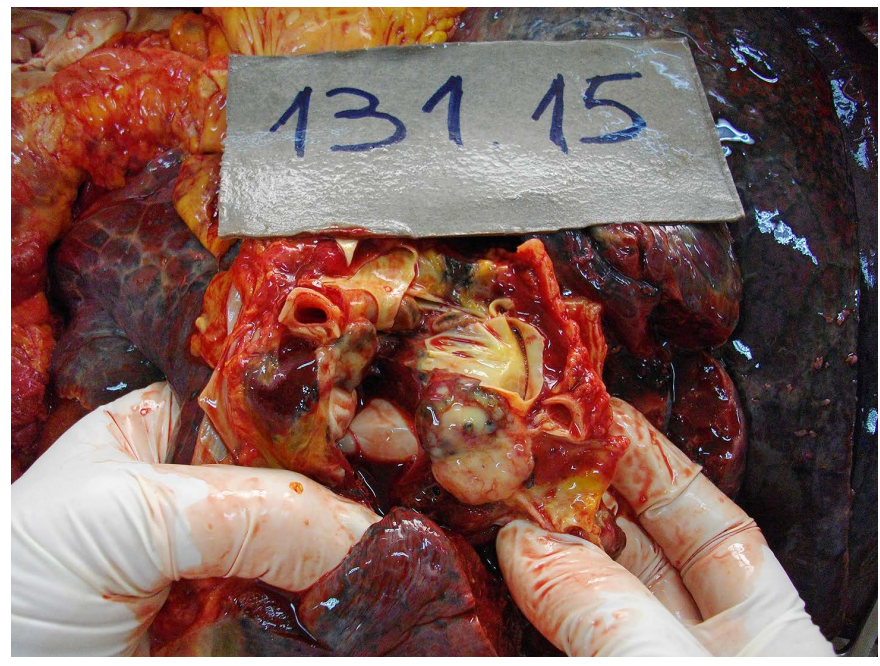

Fig. 3 Macroscopic appearance of the 25-mm white-tan, soft, friable nodule with little areas of necrosis, was identified next to the right intermediate bronchus. 


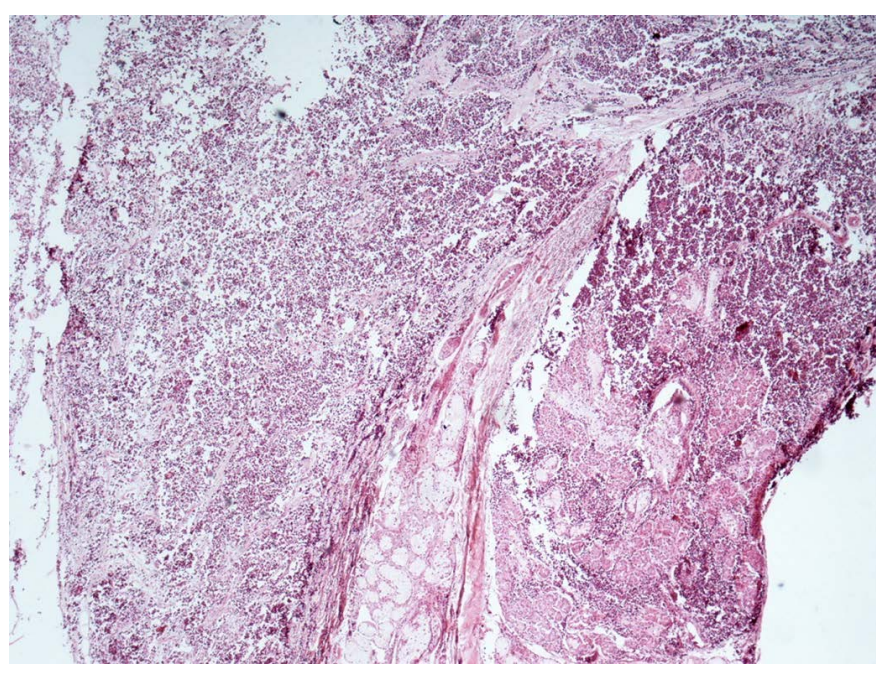

Fig. 4 Small cell carcinoma showing cells with darkly staining nuclei and scanty cytoplasm (hematoxylin-eosin stain at 4x).

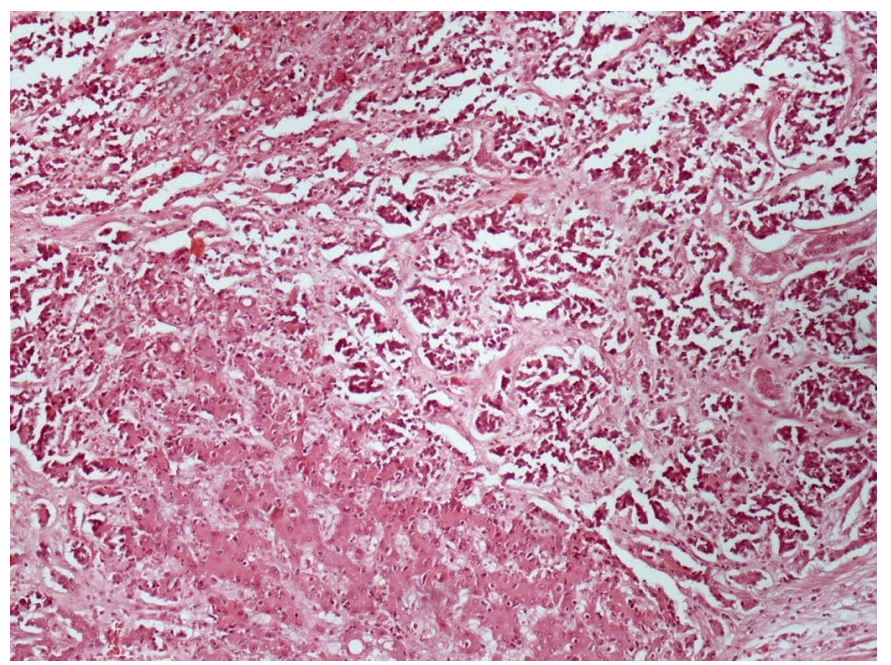

Fig. 5 Microscopic findings from the same case demonstrate a diffuse pattern of small cells infiltrating through the hepatic parenchyma (hematoxylin-eosin stain at $4 \times$ ).

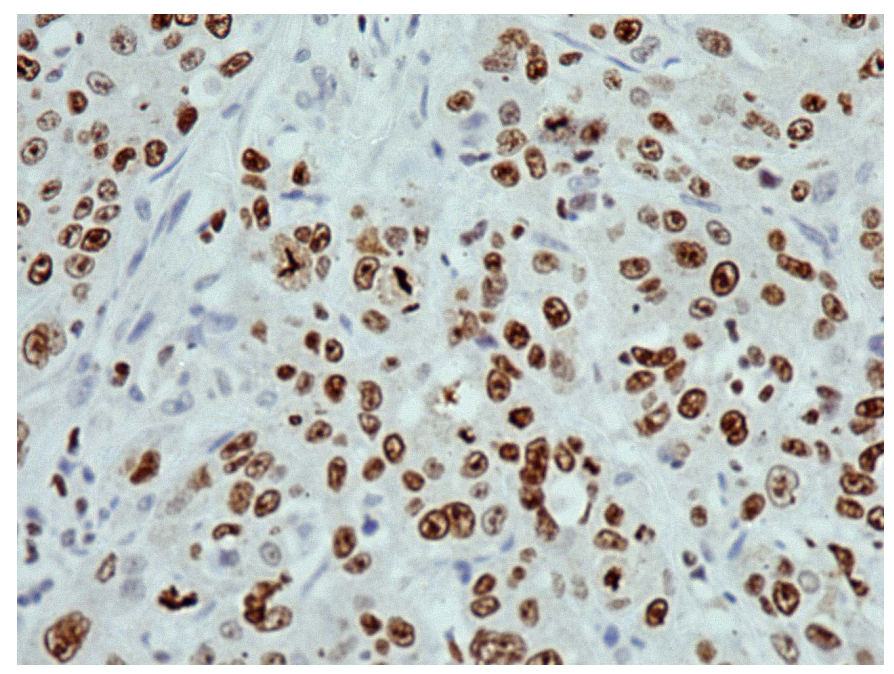

Fig. 6 TTF-1 positive staining in small cell lung cancer (Immunohistochemical stain for thyroid transcription factor-1, $40 \times)$.

\section{DISCUSSION}

Lung cancer is one of the most commonly diagnosed malignant tumor and one of the most common causes of cancer-related mortality, including the malignant mesothelioma $(6,7)$. SCLC accounts for approximately $15 \%$ of bronchogenic carcinomas and is strongly related to tobacco use (8). The likelihood of malignancy in solitary pulmonary nodules is generally related to the patient's characteristics - namely sex, age, family history of lung cancer and presence of emphysema - as well as the radiological characteristics of the nodule (9). Metastatic spread of cancer to distant organs is the main reason for the majority of malignancy-related deaths. Having studied 17,431 deceased lung cancer patients, Riihimaki et al. found out that the most usual metastatic sites of SCLC tumors are liver and central nervous system, yet liver and bone metastases signal poor survival, compared with nervous system metastases (10). Furthermore, in a retrospecrive study by Nakazawa et al. it was shown that liver metastasis was strongly correlated with poorer performance status of the patients (11). Additionally, Bremnes et al. have reported that liver metastasis was an independent prognostic factor in EDSCLC (12). Hepatic metastases are present in about $50 \%$ of patients with extensive-stage SCLC (E-D SCLC) and they can be met either as nodular lesions or as diffuse malignant infiltration of the hepatic sinusoids (5). Excessive hepatomegaly with almost complete parenchymal replacement with metastatic tumor is rarely reported. Biliary tract obstruction due to metastases to lymph nodes in the porta hepatis or hepatic parenchyma is well described and regularly met in clinical practice (13) yet fulminant and subfulminant hepatic failure with encephalopathy resulting in hepatic coma is developed in only $7 \%$ of the patients (14).

\section{CONCLUSION}

The aggressiveness of SCLC is well documented and, in many cases, metastatic lesions are diagnosed prior to the discovery of the primary tumor. It is therefore of paramount importance for the clinicians to take it into consideration in the investigation of distant metastases of unknown primary origin.

\section{REFERENCES}

1. Ost D, Fein AM, Feinsilver SH. Clinical practice. The solitary pulmonary nodule. N Engl J Med 2003; 348: 2535-2542.

2. Mosmann MP, Borba MA, de Macedo FP, Liguori Ade A, Villarim Neto A, de Lima KC. Solitary pulmonary nodule and 18F-FDG PET/CT. Part 1: epidemiology, morphological evaluation and cancer probability. Radiol Bras 2016; 49: 35-42.

3. Wahidi MM, Govert JA, Goudar RK, Gould MK, McCrory DC. Evidence for the treatment of patients with pulmonary nodules: when is it lung cancer? ACCP evidence-based clinical practice guidelines (2nd edition). Chest 2007; 132: 94S-107S.

4. Govindan R, Page N, Morgensztern D, Read W, Tierney R, Vlahiotis A, et al. Changing epidemiology of small-cell lung cancer in the United States over the last 30 years: analysis of the surveillance, epidemiologic, and end results database. J Clin Oncol 2006; 24: 4539-4544.

5. Mishima S, Nozaki Y, Mikami S, Kihira E, Iikura M, Koketsu R, et al. Diffuse Liver Metastasis of Small-Cell Lung Cancer Presenting as Acute Liver Failure and Diagnosed by Transjugular Liver Biopsy: 
A Rare Case in Whom Nodular Lesions Were Detected by Enhanced CT Examination. Case Rep Gastroenterol 2015; 9(1): 81-87.

6. Kastamoulas M, Chondrogiannis G, Kanavaros P, et al. Cytokine effects on cell survival and death of A549 lung carcinoma cells. Cytokine 2013; Mar 61(3): 816-825.

7. Galani V, Constantopoulos S, Manda-Stachouli C, et al. Additional proteins in BAL fluid of Metsovites environmentally exposed to asbestos: more evidence of "protection" against neoplasia? Chest 2002; 121(1): 273-278.

8. Alberg AJ, Ford JG, Samet JM. American College of Chest Physicians: Epidemiology of lung cancer: ACCP evidence-based clinical practice guidelines (2nd edition). Chest 2007; 132 (3 Suppl): 29S-55S.

9. McWilliams A, Tammemagi MC, Mayo JR, et al. Probability of cancer in pulmonary nodules detected on first screening CT. N Engl J Med 2013; 369(10): 910-919.
10. Riihimäki $M$, Hemminki $A$, Fallah $M$, et al. Metastatic sites and survival in lung cancer. Lung Cancer 2014; 86: 78-84.

11. Nakazawa K, Kurishima K, Tamura T, et al. Specific organ metastases and survival in small cell lung cancer Oncol Lett 2012; Oct; 4(4): 617-620.

12. Bremnes RM, Sundstrom S, Aasebø U, Kaasa S, Hatlevoll R, Aamdal S. Norweigian Lung Cancer Study Group. The value of prognostic factors in small cell lung cancer: results from a randomised multicenter study with minimum 5 year follow-up. Lung Cancer 2003; 39(3): 303-313.

13. Obara M, Satoh H, Yamashita YT, et al. Metastatic small cell lung cancer causing biliary obstruction. Med Oncol 1998; 15(4): 292-294.

14. Miyaaki H, Ichikawa T, Taura N, et al. Diffuse liver metastasis of small cell lung cancer causing marked hepatomegaly and fulminant hepatic failure. Intern Med 2010; 49: 1383-1386. 